\title{
La fe religiosa de los internos del penal Sarita Colonia del Callao-Perú
}

Un análisis psicoanalítico

\section{The religious faith of the inmates of the Sarita Colonia del Callao-Peru prison}

\section{A psychoanalytic analysis}

\section{Recibido el 17/ 09/ 2020. Revisión del 25/ 09/ 2020. Aceptado 27/09/2020}

\section{Armando Gabriel Lazarte Ugarteche}

Orcid 0000-0003-4946-5303

Universidad Nacional Mayor de San Marcos

Facultad de Psicología, Sección de Postgrado

\section{Resumen}

Este estudio exploratorio analizó desde la perspectiva del psicoanálisis el origen de la devoción religiosa en Sarita Colonia en sujetos que están privados de su libertad y cumplen condena en el Centro Penal del Callao. Para ello se realizaron entrevistas a profundidad a diez internos del Penal Sarita Colonia, siendo sus respuestas analizadas a partir de la teoría psicoanalítica de Freud, de autores post freudianos y de algunos sacerdotes católicos que han realizado investigaciones sobre las creencias religiosas populares en nuestro país. Se exponen y analizan los hallazgos, con la finalidad de generar el interés de futuros profesionales para ampliar y profundizar el conocimiento de las creencias de sujetos que se dedican a la delincuencia entendiendo que la religión forma parte de las personas (individualidades) en un marco histórico-social específico.

Palabras clave: psicoanálisis y religión, religión y delito, religión popular.

\section{Abstract}


This exploratory study analyzed under the perspective of psychoanalysis takes us to the origin of the religious devotion of Sarita Colonia to commit Crime made by subjects that are not free and serve sentence in the Penal Center of Callao. For this reason they have made profound Interviews to ten interns at Sarita Colonia Penal, answers that were analyzed based on Freud's psychoanalyst Theory, post freudians authors and some catholic priests that have made investigations of popular religious believings in our country. These findings are a exposed and analyzed with the purpose of generating interest in future professionals for them to widen and deepen the knowledge of belief in subjects that do delinquency, understanding that religion forms part of people ( individuals) in a Historic- Social specific Frame

Keywords: psychoanalysis and religion, religion and crime, popular religion.

El complejo funcionamiento psíquico de algunos delincuentes íntimamente convencidos de una fe religiosa en Sarita Colonia es también una realidad social de millares devotos ajena tanto a las autoridades como la iglesia cristiana o católica. La valoración de las pericias psicológicas en entornos judiciales y forenses suele estar ligado a la ausencia de criterios técnicos suficientes para su adecuado ejercicio (Muñoz \& López-Ossorio, 2016). La comprensión de este fenómeno puede contribuir a ampliar este panorama desde la evaluación psicológica.

El psicoanálisis presenta una manera de investigar la personalidad y características de la conducta criminal, distinta a la identificación de rasgos de personalidad y la construcción de tipologías psicológicas de la conducta, que han sido la tendencia de la psicología y psiquiatría criminal (Aguilera-Tornado, 2010).

Para los teóricos de la criminología, el delito tiene su origen en distintos factores como la irracionalidad, las desviaciones o rasgos biológicos y/o las contingencias ambientales. Mientras que para el psicoanálisis se trata de la operatoria que en cada sujeto deja a un goce interdicto y eso mismo es constatable uno por uno, no rige allí la categoría universalizante del derecho (Greiser, 2008).

Es por eso que el psicoanálisis se pregunta si no es "normal" cuestionar la propia estructura del poder social en el que estamos inmersos, el orden establecido dentro y fuera de uno mismo (Herrera, 2018). 
Es importante señalar que la construcción de la mente del ser humano empieza desde el momento de la concepción “El niño se apoya en la creación de la madre que opera en él” (Winnicott, 1982, p. 148).

Si falta esa relación afectiva inicial o si no está bien lograda deja la puerta abierta a todo tipo de problemas ulteriores. Winnicott (2007) compara a la madre suficientemente buena y la que no es suficientemente buena. En este último caso, el infante adquirirá un sentido de sumisión, construirá un conjunto falso de relaciones, y un mecanismo de defensa contra lo impensable.

Es en esos escenarios donde el inconsciente del ser humano se debe nutrir de amor esbozando, como dice Kristeva (1986) la fe, que será una energía, una inteligencia activa puesta en movimiento por el amor. Este espacio de amor empieza en la confianza en sí mismo y en el mundo que le rodea. Por eso, para creer es necesario que el "sujeto" pueda construir un vínculo de absoluta confianza con su madre. Decimos "sujeto" en el sentido que debe ser sostenido porque depende totalmente del otro que lo recibe a la vida.

La confianza en sí y en su madre es la base de las posibilidades de confianza que mañana tendrá el niño adulto, dice Winnicott (2005). Gracias a ella, y a su mirada, se juega algo decisivo en el futuro de la persona. ¿Qué ve el bebé cuando ve el rostro de su madre? La mirada de la madre y lo que su rostro expresa está en relación directa con lo que ella ve. Allí, el bebé experimenta que existe. El yo soy que está allí, el "yo soy" que allí se asienta es un acto de fe en la mirada de la madre y tiene que preceder al "yo hago". Si el "yo soy" no prende, el "yo hago" no tendrá sentido para el individuo. Es decir, la importancia de la relación afectiva que se construye en ese momento es la clave de "ser" (Santuc, 2005).

Cuando en la infancia está ausente la ternura de la madre, nada puede representar al objeto madre, sino la ausencia y esa ausencia afectiva deja al niño expuesto a construir imaginariamente ese amor materno ausente. El niño ya no necesita de la presencia del cuerpo de la madre sino del placer de pensar, primero con ella, y luego para sí mismo. Sería una ilusión, su propia capacidad de crear esa madre que él necesita, porque la ausencia de amor y cuidados de los padres o cuidadores deja expuesto al niño a no poder 
completar, formar, una estructura psíquica que satisfaga su deseo de amor (Kristeva, 2009).

La incapacidad de las estructuras psíquicas para satisfacer las demandas reales de amor es una de las características de las neurosis, que pueden llegar a la psicosis cuando el sujeto está dominado por la oposición entre la realidad y la fantasía. Frente a esa falta de amor el sujeto huye de lo que desea y es más intenso en sus fantasías si se encuentran con la vida real, siendo más propensos a abandonarse a esas fantasías cuando ya no tienen que temer su realización (Freud, 1927).

Para Winnicott (1965), desde el nacimiento se establecen las raíces de lo que cada uno de nosotros seremos en la edad adulta. El bebé no es una entidad autónoma y solo se le puede comprender si ha sido amparado por la madre y articulado en el ambiente que lo rodea: "La fe es la base del sujeto". La confianza del niño en sí es lo que asienta "las posibilidades de confianza" cuando sea adulto. Un aspecto importante en el asentamiento de la fe es que al comienzo de la vida "la madre le permite al bebe hacerse la ilusión de que su seno es una parte de él, lo mismo para otras atenciones: tiene hambre, llora, allí está el seno; grita y allí está la madre” ¿Qué es esta experiencia? "Es experiencia de omnipotencia" (Santuc, 2005, p. 224). ¿Qué quiere decir esto?, se pregunta. "La adaptación de la madre al niño le dará a este la ilusión de una realidad exterior”.

"Ser un niño no querido, ser pasado de una persona a otra en los primeros meses de vida, predispone a una enfermedad antisocial...Puede o no tener sentido, pero no olvido mi experiencia clínica sobre la relación entre no ser querido al comienzo de la vida y la posterior tendencia antisocial" (Winnicott, 1999, p. 89).

La madre instituida por el bebé no se da inmediatamente en los sentidos, sino en lo que ha sido creado simbólicamente por él. Es decir, la madre del bebé es una madre simbólica y en un proceso de análisis el sujeto tiene que aprender a comprender que la madre que él ha construido a lo largo de su vida es la madre real y no la madre simbólica que le dio en la primera etapa de su vida una seguridad.

La identificación emocional del bebé con la madre permite sostener al Yo inmaduro generando en el nuevo ser la experiencia de continuidad de existir. Si fracasa, el sujeto vive amenazado por las angustias primitivas promoviendo defensas tempranas o a un auto 
sostenimiento precoz y defensivo. Estas vivencias dejan una marca traumática que queda inscrito en el inconsciente no reprimido, sin acceso al recuerdo ni a la palabra, pero con potencialidad de actualizarse en vivencias angustiosas sostiene (Abadi, 1996).

Es por eso que el psicoanálisis no solo plantea una contribución en el campo de la psicopatología sino también a la condición humana y a su campo de acción, y con la consiguiente responsabilidad puede revelar aspectos ocultos de las colectividades humanas (Herrera, 2018).

En este sentido el punto de estudio del análisis de la actividad predictiva es definir en forma clara y operativa cuál es la influencia de la creencia de una fe religiosa para delinquir, teniente en cuenta lo mencionado por Freud de que no se trata de fundar una religión sino sublimar la necesidad de creer (Kristeva, 2009).

Para Santuc (2005) existen muchas razones para afirmar que Freud ha abierto una nueva manera de concebir al hombre, una ruptura con lo anterior a él. Con Freud se mira la vida humana como espiritual y corporal en todo momento. La vida humana y todo lo de la vida humana están siempre apoyados en el cuerpo y en su relación con los demás.

El hombre es un ser en permanente construcción, una historia que es una historia de su cuerpo y de sus relaciones con el entorno. La génesis del sujeto es contemporánea a su propia historia. Es un espacio donde se abren posibilidades o imposibilidades según sus experiencias afectivas iniciales (Santuc, 2005).

En el lenguaje inicial de todo niño, cuando aparece la comprensión y simbolización, es como el verdadero espacio de nacimiento del sujeto y de la capacidad de relacionarse consigo mismo y con los demás, pero, no se puede separar el lenguaje y el afecto (Santuc, 2005). Sin la relación afectiva inicial, el sujeto no sale de cierta indiferenciación.

Podemos decir que el creer es lo que hace al sujeto y eso se juega desde la etapa del bebe que cree absolutamente en su madre y en las palabras que ella dice. La confianza del niño en sí y en su madre es lo que asienta posibilidades de confianza que mañana tendrá el niño adulto (Winnicott, 1965). El afecto da consistencia al ser.

Para Balint (1993) la falta de ajuste en la relación del niño con el objeto primario ha dado como resultado el nacimiento de la agresividad. Según la teoría de los Defectos 
básicos, incluso el narcisismo, que para Freud era el tipo primario (fase normal del desarrollo sexual) y secundario (patológico), se considera solamente secundario, causado por la falta de amor recibido por el niño por parte del objeto principal, que le lleva a rebelarse de manera similar, la envidia. Esta protege al individuo de sentimientos perturbadores como el vacío y la desolación, conllevando a la fantasía omnipotente de que uno puede robar lo que no tiene de otra persona, y destruir el resto que es envidiado.

Si es deseo del objeto o de lo que el objeto tiene, no es el tema, en cambio la envidia gira en torno al conjunto de deseos y fantasías primitivos de que desaparezca aquello que nos hace diferentes al objeto materno. La rabia del que envidia elimina de raíz cualquier tipo de sentimiento amor y gratitud, y solo se sacia cuando se ensaña en la destrucción del otro al costo que sea, incluso del propio.

Es así como puede verse cómo la envidia, que va alimentándose poco a poco, estalla cuando una circunstancia aparentemente menor, de pronto produce la pérdida del control de los impulsos del odio y, como consecuencia, el paso a la acción.

En el Porvenir de una Ilusión, Freud (1927), se ocupa de la naturaleza psicológica de las representaciones religiosas en cuanto ilusiones y no en su contenido de verdad, en cuanto realidad. Califica de ilusión una creencia cuando aparece engendrada por el impulso a la satisfacción de un deseo, prescindiendo de su relación con la realidad. Así podríamos asociar un acto delictivo cuando el delincuente considera que se están dando las condiciones para actuar. Este autor afirma que el predominio de la vida imaginativa y de la ilusión sustentada por el deseo insatisfecho es un fenómeno característico de las neurosis que pueden hacer actuar a una persona en forma agresiva o depresiva. También lo podemos observar en las pandillas, organizadas como un psiquismo primitivo, que construyen ilusiones y no la verdad. Podemos distinguir que un factor de cohesión de una pandilla es la homogeneidad mental generada por un interés común, por ejemplo, robar, por el mismo sentimiento en relación a una idea o situación y por la capacidad de influenciarse mutuamente.

Para Bollas (2018) en nuestro proceso de desarrollo existe una relación intrasubjetiva, es decir, con nosotros mismos. ¿Qué tipo de conversación tenemos con nosotros mismos? En el caso de la etapa adolescente, el sujeto tiene un Yo incompleto, 
por eso muchas veces tiene que fingir. Muchos episodios psicóticos son transitorios en esa etapa y en algunos casos aparecen las enfermedades mentales más importantes. La adolescencia es un periodo con tendencia a la idealización y/o con pensamientos de genialidad. Este autor explica que en Gran Bretaña la idealización (inconsciente) se ve como un estado mental psicótico, es por eso, señala, que muchos jóvenes se incorporan a ISIS o viajan a Siria y otros se incorporan al Cuerpo de Paz o al habitat para la humanidad.

No existe mucha evidencia documentada acerca de delincuentes que creen que sus actos tienen una justificación religiosa, pero esta relación está cada día más extendida por el consumo y tráfico de drogas, costumbres ancestrales y culturas marginales. La mayor parte de los estudios sobre la influencia religiosa se refieren a ayudar al delincuente a reivindicarse con la sociedad, mas no a considerar que su fe justifica una conducta delictiva como es la devoción de algunos sectores que se sienten marginados y buscan la protección de figuras humanas a las que le atribuyen poderes milagrosos como es el caso en el Perú de la devoción que le rinden algunos santos del pueblo, no solo los delincuentes, sino de miles de personas especialmente de sectores populares para agradecerle por los milagros concedidos o rogarle para que los ayude a proteger a sus familias. Es una fe construida para llenar un vacío o ausencia de amor o insuficiente atención de la madre que le genera angustia como sostiene Freud.

Uno de los casos más emblemáticos son los devotos de Sarita Colonia, que se considera tiene una connotación inconsciente de la representación de la Virgen María porque le atribuyen poderes sobrenaturales y hace milagros, los protege, ayuda y perdona. Incluso, en el caso de los delincuentes devotos, pueden regresar a la cárcel después de haberlos ayudado a salir libres, pero no pierden la fe en ella porque consideran que Sarita está por encima de todo mal y tiene el poder de interceder ante Dios para obtener su perdón.

¿Quién fue y qué representa Sarita Colonia para sus creyentes devotos? Un informe publicado por el diario El Comercio de Lima, Jáuregui, (2002) señala que "sus devotos profesan una fe que mueve montañas y que echa por tierra la lógica de los santos oficiales. Entre el agua bendita, el sudor de sus fieles y los tatuajes y cicatrices de sus creyentes, la santa de los humildes recibe multitudes en sus aposentos" (p. 5). 
Según los registros históricos, Sarita Colonia Zambrano nació en el caserío de Belén en 1914, en Huaraz, Ancash. Fue hija de don Amadeo Colonia un carpintero de la zona y de Rosalía Zambrano, ama de casa. De acuerdo con los registros oficiales Sarita muere el 20 de diciembre de 1940 a los 26 años en el hospital de Bellavista del Callao. Existe confusión sobre la causa de su muerte. Oficialmente en la partida de defunción registra que murió de paludismo, aunque sus hermanos sostienen que su muerte se debió a una sobredosis de aceite de resina. Sin embargo, en la mitología popular se cuenta que la muerte de Sarita se debió cuando ella se arrojó al mar para evitar ser violada.

Hasta la fecha no existe seguridad a dónde fueron sepultados sus restos. Existe la versión de que fue enterrada en una fosa común del cementerio Baquijano del Callao, pero las autoridades del puerto intentaron allanar la fosa común para ampliar el cementerio y un grupo de pobladores impidió su demolición y levantaron una capilla en homenaje a Sarita Colonia que hoy es visitada por miles de fieles.

A pesar del tiempo transcurrido, el culto a Sarita sigue creciendo en el pueblo. Los vehículos de transporte público llevan su imagen, se distribuye su foto, se hacen canciones, documentales y hasta series de televisión. Un reciente documental titulado "La Tregua Moral" de Ponce Gambirazo, muestra un trabajo de investigación y homenaje a Sarita Colonia en el que entrevista a varios delincuentes que confiesan su fe para poder justificar cuando delinquen.

Como se ha señalado anteriormente, para el psicoanálisis, lo particular en el proceso de estructuración de la vida psíquica es la forma como esa ley natural reorienta el deseo en cada sujeto en la primera etapa de la vida. Ante la ausencia de la madre real, el vacío que deja esa madre biológica, el niño construye una madre idealizada.

Por ese motivo, para comprender cualquier religión hay que establecer una distinción entre la religión como sistema o estructura y la práctica o actuación de la religión en la vida cotidiana de los creyentes. Comprenderemos entonces que hay un gran vacío que explique el significado de la religión en los dos niveles: creencia y práctica.

El enigma son las prácticas religiosas populares que no distinguen lo bueno de lo malo, ni a los ricos de los pobres, a hombres o mujeres, al criminal o al inocente sino a la justificación de un amor divino que libra de toda culpa y perdona. "La religión no existe 
por sí sola, sino que es vivida por personas concretas dentro de situaciones históricas y sociales específicas” (Regan, 2011, p. 16).

La familia peruana no inicia a sus miembros en el catolicismo en general, sino en el catolicismo tal como se vive en la "religión popular" (González, 1984). Para Regan (2011, p. 13) la religión del pueblo significa todos los fenómenos religiosos vividos en el pueblo y no solo el comprendido en el catolicismo formal. Se trata de la totalidad de sentimientos acerca del mundo sobrenatural, las practicas rituales y las normas morales de conducta individual y social.

Las creencias religiosas populares siempre han existido, pero la mayoría de las religiones antiguas eran locales y exclusivas. Hoy a lo popular se le vincula con la población que está al margen, a los que no están reconocidos de los derechos y beneficios sociales. Por eso, el pueblo experimenta que esas imágenes religiosas son poderosas y continúa acudiendo a ellas. Quizás ese es el motivo por el que la religiosidad oficial verá con preocupación devociones como la de Sarita Colonia, la Beatita de Humay u otras, ya que, efectivamente, no los reconoce como "santos verdaderos" a pesar de que la población que si creen en ellos perciben que les hacen milagros.

Para Marzal (1990) la religión del pueblo es el conjunto de significados personales a los conceptos de devoción, santo, milagro, promesa, bendición, fiesta y peregrinación, así como de convicciones individuales que si bien no se desprenden de la verificación y la experimentación ni de la manera de los modos de reconocimiento y control le dan sentido al que hacer de las personas, así como también al de los delincuentes y coherencia a su acto delictivo.

El porqué de esa costumbre no es fácilmente comprensible porque el creyente no necesita lógica, cumple con su acto de fe, de confianza o de adoración y esto no requiere demostración para él porque es algo que está en su inconsciente. Es en ese sentido donde la fe nos muestra que es el núcleo auténtico sobre el que se edifica todo sistema religioso y esa es la fe que se construyó en presencia o ausencia de la madre.

Para el psicoanálisis, según Winnicott, la madre no es la madre en sí (desde una perspectiva solo biológica) sino la madre de la relación constituida o instituida por el sujeto. "El niño se apoya en la creación que opera en él, crea a partir de la ausencia, pero 
ni podría crear sin la presencia anterior de la madre suficientemente buena, ni podría sin la ausencia anterior de esa misma madre" (Santuc, 2005, p. 228), eso indica para el autor, cómo una madre demasiado presente (sobreprotectora) igual que una madre demasiado ausente no posibilita la creación.

El actual Papa Francisco (2018) en una de las reuniones que suele llevar a cabo con los cristianos católicos en el sur Italia relató una historia de la devoción de los ladrones de la "Virgen de los Mandarinos". Según contó en una charla que está grabada y que puede verse en internet, esa devoción es una "fe folklórica y popular", una teología muy grande -señala- porque una madre cuida a sus hijos hasta el fin, A un devoto de María no se le condena, afirma en esa conferencia.

Sarita Colonia sería esa imagen de la madre ideal psíquicamente anhelada. La devoción a su figura le otorga la categoría de madre espiritual hasta elevarla a la categoría de una santidad como el de la Virgen Madre de Dios, aunque ellos no lo mencionan expresamente, pero tiene el mismo poder de influir ante el Padre Celestial para perdonar todos los pecados.

Esta visión de la religión no es exclusiva de los delincuentes. Gente aparentemente "normal", tiene ideas parecidas, inculcadas por la educación que reciben. El buen comerciante reza para que le salga bien el negocio en el que piensa engañar a alguien.

En el Cusco existe la devoción al Niño Compadrito, “a pesar de su ubicación en una capilla rustica de un feligrés, el Niño Compadrito atrae a tantos piadosos como las versiones del Niño Dios autorizadas por la iglesia católica” (Kato, 2001, p. 136).

El autor señala que la fe en el Niño Compadrito es un resultado paulatinamente acumulado de las "acciones cooperativas" conscientes o no de los devotos, que se inician sobre todo en la década de 1950. "Por la evaluación del pueblo que cree en él y que confirma lo que podríamos llamar la mentalidad colectiva (Kato, 2001, p. 154).

En México existe el culto a la Santa Muerte, una religión popular que combina los aspectos tradicionales del catolicismo con la antigua religiosidad azteca para formar una nueva fe. Como santa patrona de la muerte, la Santa Muerte es una especie de protector 
espiritual para una creciente legión de mexicanos que se sienten desprotegidos por el Estado y desechados por la Iglesia Católica.

Es así como cada grupo social puede tener una versión distinta, como señala Durkheim. Por esta razón podríamos entender que la población marginal -como todo grupo humano- necesita un referente que llene este vacío. Freud pensaba que no se trata de fundar una religión, sino de "sublimar" la necesidad de Creer (Kristeva, 2009).

En el "Porvenir de una Ilusión" Freud (1927) vislumbra:

"Existe una clase de hombres, los neuróticos, en los que ya estas interdicciones provocan una reacción asocial. Tales deseos instintivos son el incesto, el canibalismo y el homicidio. La intensidad de los deseos incestuosos se hace aún sentir detrás de la prohibición, y el homicidio es todavía practicado e incluso ordenado en nuestra cultura bajo determinadas condiciones". (Freud, 1927, p. 10).

Klein (1987) señala que, con el transcurso del tiempo, los hallazgos de Freud nos han ayudado a comprender la complejidad de las emociones infantiles y han revelado que los niños atraviesan por serios conflictos. Ello permite lograr una mejor comprensión de la mente infantil y de su relación con los procesos mentales del adulto.

En la Teología de la Liberación se vislumbra que el pobre tiene muchas veces una cultura con sus propios valores; ser pobre es un modo de vivir, sostiene, de pensar, de amar, de orar, de creer y esperar...y después señala que la comunidad cristiana deberá en adelante a vivir y celebrar su fe en un mundo no religioso que la fe misma ha contribuido a promover (Gutiérrez, 1981).

Al presentar este artículo, coincidimos con Gutiérrez (1981, p. 104) cuando concluye que "para Freud la represión es el resultado del conflicto entre las pulsiones instintivas y las exigencias culturales y éticas del medio social. Las motivaciones inconscientes ejercen un poder tiránico y pueden dar lugar a conductas aberrantes que solo son controlables si se toma consciencia de esas motivaciones, a través de una lectura apropiada del nuevo lenguaje de significaciones creada por el inconsciente". 
Y ese inconsciente empieza a construirse desde el nacimiento con la presencia de la madre y el ambiente facilitador:

Conociendo de cerca las tradiciones, los problemas y las inquietudes de los pueblos marginados, podemos lograr una mayor solidaridad con ellos. Sin embargo, el dialogo no debe limitarse a esta dimensión. Vivimos en una sociedad moderna que va perdiendo contacto con sus raíces históricas y se va comprometiendo con su consumismo del alma. El contacto con las tradiciones del pueblo nos enriquece y nos cuestiona (Regan, 2011, p. 17).

\section{Objetivos}

Este estudio, partiendo de un enfoque psicoanalítico, se propone:

- Analizar la interacción de factores de riesgo delictivo y protección religiosa en reclusos del Centro Penal del Callao

- Interpretar el sistema de creencias de justificación religiosa basada en la necesidad de aferrarse el culto a Sarita Colonia.

\section{Método}

La presente investigación es de tipo cualitativa y de carácter fenomenológico, pues se pretende recabar las experiencias individuales subjetivas de los participantes y a partir de ella, interpretativamente reconocer las experiencias de fe y delito en reclusos del Penal del Callao (Hernández, Fernández \& Baptista, 2010).

\section{Participantes}

Para lograr los objetivos planteados, esta investigación se realizó en el Centro Penal del Callao, próximo al Asentamiento Humano conocido con el nombre de Sarita Colonia. 
Este reclusorio alberga aproximadamente a cuatro mil personas, pese a que fue construido para recibir a 650 sujetos. Existe hacinamiento y son escasos los recursos para atender a toda su población.

De este centro se tomó como muestra a diez presos por delitos comunes, obtenidos a través de un muestreo probabilístico incidental. Para que pudiesen fungir de participantes, se consideró que cumplieran con las siguientes características: aceptar el consentimiento informado, que tuviesen tatuajes en su cuerpo con la imagen de Sarita Colonia y que no tuvieran enfermedades graves o sintomatología psiquiátrica.

Así, los entrevistados fueron presos identificados por su devoción a Sarita Colonia y seleccionados durante los días de las entrevistas por las autoridades del departamento de psicología de dicho penal.

\section{Instrumento}

Para la recolección de la información, se creó y validó una guía de preguntas a ser empleadas en las entrevistas, las cuales estuvieron relacionadas a la fe en Sarita, a las prácticas o rituales religiosos y a la racionalización de los actos delictivos para evitar ser descubiertos o capturados. Para ello se empleó como método de validación el juicio de expertos, donde tres jueces analizaron y valoraron la pertinencia, relevancia y claridad de las preguntas formuladas, siendo todas aprobadas. Ellos fueron los doctores Jaime Aliaga Tovar, Dr. en Psicología; Mariano Querol, Dr. Emérito en Psiquiatría y Natalia Ramírez, Dra. en Estudios Interdisciplinarios de Género.

Estas también fueron presentadas por la dirección de Post Grado de la Facultad de Psicología de la Universidad Nacional Mayor de San Marcos a las autoridades del Instituto Nacional Penitenciario (INPE), quienes dieron su conformidad y curso al trabajo. 


\section{Procedimiento}

Con las autorizaciones por parte de las autoridades del penal, se procedió a realizar las entrevistas semiestructuradas, las que se llevaron a cabo en el contexto de un diálogo de corte psicoanalítico donde los entrevistados se sintieran libres de responder, preguntar o guardar silencio y el entrevistador sin memoria ni deseo o presión.

Estas se realizaron en una oficina del departamento de psicología, facilitada por las autoridades. Gracias a esta facilidad se pudo dialogar con los internos al principio con cierta desconfianza, pero luego de explicarles el propósito de nuestra investigación y la libertad que tenían para responder y participar colaboraron abiertamente. A todos se les pidió una declaración de conformidad escrita y firmada de puño y letra autorizando la entrevista.

\section{Resultados ${ }^{1}$}

A continuación, a partir de la información recogida por medio de las entrevistas, sobre las que se realizó un análisis de contenido y se encontraron los siguientes resultados.

Para comprender las motivaciones de algunos delincuentes que tienen fe en Sarita Colonia tenemos que analizar desde el psicoanálisis cómo está estructurado el psiquismo a través de su historia y desarrollo. Es decir, reconstruir su pasado y las huellas psíquicas que han generado sus representaciones inconscientes, así como sus regiones enigmáticas como son sus experiencias religiosas.

"Los seres humanos aprendemos a confiar en la realidad, siempre y cuando esta se muestre confiable desde que somos pequeños. Esta constancia de realidad, como le llaman algunos, supone la presencia de adultos seguros de sí mismos, constantes en su soporte emocional, sino también que lo que percibimos ayer, permanezca hoy en el mismo lugar y con las mismas características” (Herrera, 2018, p. 137).

1 Se emplean citas entre comillas (“...”) para ejemplificar los temas señalados. 
Nos hemos propuesto el objetivo de interpretar que existe el sistema de interacción de factores de riesgo delictivo y protección religiosa en reclusos devotos del penal Sarita Colonia. Y hemos constatado en todas las entrevistas que existen y no ocultan esa fe. Al contrario, es una devoción que los inspira a pedirle que los "cuide" y también a sus familias mientras están presos, lo que tiene un sentido más profundo de la fe que practican porque al estar privados de su libertad sienten que han abandonado a sus familias frente a los peligros del medio en el que viven. Es una fe que va más allá de la conducta vinculada al delito, pero la iglesia católica no lo registra para hacer una labor pastoral.

Los delincuentes que tienen las creencias para justificar la conducta delictiva, basada en el culto a Sarita Colonia, han sido aprendidas a partir de tradiciones familiares y compañeros delincuentes dentro y fuera del penal. Esta influencia es cada día más extendida debido a que no tienen límites morales ante una sociedad que los margina y los condena al castigo.

El vínculo de estos sujetos entre sus creencias religiosas y delinquir lo demuestran con orgullo al exhibir tatuajes, rendirle culto, visitar el mausoleo, llevarle flores y rezar. "No es fácil tratar temas delicados y conflictivos como la realidad que queremos penetrar con los ojos de la fe" (Gutiérrez, 2015, p.11).

La fe religiosa de los delincuentes entrevistados cuando cometen un acto delictivo se debe entender en su propio contexto relativo. Las personas entrevistadas provienen de hogares donde el padre y la madre, ya sea por abandono o trabajo han estado ausentes desde su infancia, y esto se refleja en algunos de los testimonios: "Mi mamá era muy severa, me castigaba con chicote, mi papá era alcohólico...", “Mi mamá trabajaba y nunca teníamos lo suficiente...”.

Algunos entrevistados empezaron a delinquir desde su temprana edad porque crecieron con la "ley de la calle", sin protección, sin el afecto y ausencia del cuidado de los padres, así uno de ellos nos cuenta: “...el primer delito lo cometí a los ocho años y desde esa edad soy devoto de Sarita".

\section{Discusión}


Esta investigación tuvo como objetivo explorar desde el psicoanálisis que la pobreza no solo es de carencia económica y falta de servicios básicos, sino un cuidado pediátrico asistencial donde en este trabajo no pueden estar ajenos los padres, los custodios de toda índole, escuelas de diverso tipo y otros factores ambientales que son el futuro de nuestra sociedad. Las controversias pueden subsistir porque el acceso al psicoanálisis que en el Perú ha estado limitado, pero felizmente ya se enseña en algunas universidades de nuestro país. En la realidad se requiere una nueva política de Estado donde el psicoanálisis pueda contribuir a presentar una manera de investigar la personalidad y características de la conducta criminal, distinta a la identificación de rasgos de personalidad y la construcción de tipologías psicológicas de la conducta, que han sido la tendencia de la psicología y psiquiatría criminal (Aguilera-Tornado, 2010).

Los trabajos que influyeron en la motivación de este estudio fueron la teoría psicoanalítica de Freud, autores post freudianos que han estudiado el origen de la construcción psíquica y el desarrollo personal, así como los de algunos sacerdotes católicos que han realizados investigaciones sobre las creencias religiosas populares en nuestro país. Algunos de estos religiosos de prestigio reconocen en el psicoanálisis una fuente importante de interpretación de la conducta humana y sus creencias.

Así, se analizó desde la perspectiva del psicoanálisis, el origen de la devoción religiosa en Sarita Colonia para delinquir en sujetos que están privados de su libertad y cumplen condena en el Centro Penal del Callao. Al tomar como marco de referencial el psicoanálisis se ha tomado distancia de la criminología, teología y antropología porque no se trata de la creencia de una religión institucional, sino de sentimientos de un mundo sobrenatural para la conducta inconsciente individual o social.

Al concluir, no se puede dejar de mencionar la importancia de las prácticas religiosas en las cárceles. La visita de pastores de distintas creencias religiosas tiene una labor importante porque acompaña a los presos frente a la soledad y les da esperanzas de recuperación con sus familias y sociales.

Es preciso señalar que no todos los devotos de Sarita Colonia, son personas que han cometido o cometen delitos como los que actualmente están presos y tienen fe en ella. Al contrario, esa devoción no tiene límites y miles de sus feligreses creen en su capacidad 
milagrosa, cualquiera que sea su historia. Para eso han construido y visitan una Cripta en el cementerio del Callao donde se venden todo tipo de recuerdos con su imagen recordatoria y oraciones.

La experiencia de este estudio nos lleva a la necesidad de comprender que la dramática historia del ambiente y de sus carencias, como el de los sujetos entrevistados, requiere de una urgente y profunda política social que no se limite a atender algunos aspectos básicos de infraestructura, como escuelas y salud pública, sino a proteger a la familia desde una perspectiva pediátrica, como señala Winnicott. Desde la concepción, la madre necesita ayuda y protección afectiva y económica. El vínculo que se construye en el momento del nacimiento del nuevo ser necesita asistencia. Una labor en ese sentido es el que realiza desde hace treinta años La Casa de la Familia en el distrito del Rímac donde psicoanalistas y psicólogos dan acogida a familias y niños hasta la edad adolescente.

El modelo creado en Brasil denominado Asociación de Protección y Asistencia a los Condenados (APAC) ha desarrollado un criterio importante después del "fenómeno" del proselitismo religioso en las cárceles consideradas como amenaza para la seguridad del Estado y los ciudadanos por la radicalización religiosa, en particular musulmana, según señala La Torré (2016) "Los actores implicados en esos dispositivos son voluntarios religiosos, en su mayoría laicos, que proponen a detenidos voluntarios y acreditados, por un tiempo determinado un sistema de actividades religiosas y otras seculares" (p. 208).

La investigación psicológica plantea extrañas motivaciones del analista, en particular, cuando se trata de comprender el alma humana, al que Freud lo llamó el "inconsciente reprimido". "El problema no está en la profundidad de aquello de lo cual el individuo no es consciente, sino en lo que el inconsciente no puede recordarse porque está asociado a un sentimiento penoso o a alguna otra emoción intolerable y es fácil ver que si una gran parte de la personalidad de un individuo está reprimida, le queda comparativamente poca energía para su participación directa en la vida" (Winnicott, 1999, p. 44). 
Finalmente, con lo presentado y analizado, se pretende alentar el interés de futuros profesionales para ampliar y profundizar el conocimiento de una creencia de sujetos que se dedican a la delincuencia.

\section{Agradecimientos}

Deseo expresar mi sincero agradecimiento al Instituto Nacional Penitenciario (INPE), en especial a su Director General de Tratamiento, señor Dr. Marlon Florentini, quien desde un inicio comprendió la importancia de la investigación de orientación psicoanalítica que propusimos a su institución. Asimismo, extiendo ese agradecimiento al Departamento de Psicología del Penal Sarita Colonia que en todo momento brindo facilidades de infraestructura para las entrevistas. No podría omitir mi agradecimiento a los sujetos que cumplen una pena de carcelería y me confiaron aspectos importantes de sus vidas para el estudio.

\section{Fuentes de Financiamiento}

El presente estudio ha sido autofinanciado con recursos propios, incluyendo compra de libros y consultas a especialistas profesionales y gastos materiales.

\section{Rol del autor}

Asumí este proyecto inspirado en la Maestría de Riesgo Psicosocial para la Seguridad Ciudadana y la necesidad de hacer algún aporte a la sociedad que atravesaba por una creciente inseguridad ante los robos y asesinatos.

\section{Aspectos Éticos y Legales}

El suscrito declara bajo juramento su respeto a los códigos de investigación con humanos reseñados en la confidencialidad de las entrevistas. En ese sentido he procurado la protección de la confidencialidad de la información personal e institucional, asegurando el anonimato de los participantes, así como de las personas e instituciones involucradas. De manera expresa afirmo que se han respetado las normas éticas que regulan el ejercicio profesional (Código de Ética del Colegio de Psicólogos del Perú).

\section{Conflicto de intereses}

El autor manifiesta no haber tenido ningún conflicto de intereses al realizar esta investigación y artículo y declara bajo juramento haber respetado este principio. 


\section{Referencias}

Abadi, S. (1996). Transiciones. El modelo terapéutico D. W. Winnicott. Buenos Aires: Lumen.

Aguilera-Torrado, A. (2010). Explicación psicoanalítica del acto criminal. Criminalidad, 52 (1), 333-348. Recuperado de https://dialnet.unirioja.es/servlet/articulo?codigo=3621635

Balint, M. (1993). La falta básica: Aspectos terapéuticos de la regresión. Barcelona: Paidós.

Bollas, C. (2018). Meaning and melancholia: Life in the age of bewilderment. New York: Routledge.

Freud, S. (1990). Fragmento de análisis de un caso de histeria (Dora). (1905 [1901]. Obras Completas. En Tomo VII. Buenos Aires: Amorrortu.

Freud, S. (1927). El porvenir de una ilusión. Obras Completas, Buenos Aires: Amorrortu.

Francisco, Papa Pontífice, Los Granujas pueden ir al cielo, El Observador, obserbvacatholic.com (Youtube 2018)

Greiser, I. (2008). ¿Qué es lo que el psicoanálisis puede aportar a la criminología? Virtualia, $18 . \quad$ Recuperado de http://www.revistavirtualia.com/articulos/422/dossier-psicoanalisis-ycriminologia/que-es-lo-que-el-psicoanalisis-puede-aportar-a-la-criminologia

Gonzáles, J. (1984). Familia y socialización religiosa. La transmisión de la religiosidad popular en el Perú. Revista de la Universidad Católica, 15-16. 55-80. Recuperado de http://repositorio.pucp.edu.pe/index/handle/123456789/49271

Gutiérrez, G. (2015). Teología de la liberación: perspectivas. Lima: Centro de Estudios y Publicaciones.

Jauregui, D. (31 de noviembre de 2002). Rezando en jerga. El Comercio, pp. 3-6.

Kato, T. (2001). Historia tejida por los sueños: formación de la imagen del niño compadrito. En Tomoeda, H., Millones L. \& Kato, T. (Ed.). Dioses y demonios del Cuzco. 99-162. Lima: Congreso del Perú.

La Torré, A. (2016). Cárceles APAC en Brasil: ¿lo religioso como nuevo paradigma de gobernanza en el ámbito carcelario? En Constant, C. (Ed.). Pensar las cárceles de América Latina. Lima: Instituto Francés de Estudios Andinos, Instituto de Estudios Peruanos y Pontificia Universidad Católica del Perú.

Hernández, F., Fernández, C. Baptista, L. (2010). Metodología de la investigación. México: McGraw Hill. 
Hernandez Lefranc, H. (2007). Sarita Colonia: estetización del ícono y uso de imágenes ¿para la autonomía cultural? Investigaciones Sociales, 11 (19). 55-68. Recuperado de https://doi.org/10.15381/is.v11i19.8045

Herrera, L. (2018). Reflexiones Psicoanalíticas sobre la violencia y el poder en el Perú. Lima: Biblioteca Peruana de Psicoanálisis.

Klein, M. (1987). Nuestro mundo adulto y sus raíces en la infancia (1959). Obras completas. Buenos Aires: Paidós.

Kristeva, J. (2009). Esa increíble necesidad de creer. Buenos Aires: Paidós.

Kristeva. J. (1986). Al comienzo era el amor, Psicoanálisis y Fé. Buenos Aires: Gedisa.

Marzal, M. (1990). Claves de interpretación para el catolicismo popular peruano. Diálogos de la comunicación, 28, 37-44. Recuperado de https://dialnet.unirioja.es/servlet/articulo?codigo=2700999

Muñoz, J. \& López-Ossorio, J. (2016). Valoración psicológica del riego de violencia: alcance y limitaciones para su uso en el contexto forense. Anuario de Psicología Jurídica, 26 (1), 130-140. Recuperado de https://www.redalyc.org/articulo.oa?id=315046741016

Regan, J. (2011). Hacia la tierra sin mal: Estudio sobre la religiosidad del pueblo en la Amazonía. Lima: Centro de Estudios Teológicos de la Amazonía.

Santuc, V. (2005). El topo en su laberinto: Introducción a un filosofar posible hoy. Lima: Universidad Antonio Ruiz de Montoya. Areté, 18 (1), 177-179. Recuperado de http://revistas.pucp.edu.pe/index.php/arete/article/view/413

Winnicott, D.W. (1982). Realidad y juego. Buenos Aires: Gedisa.

Winnicott, D. W. (1965). El niño y el mundo externo. Buenos Aires: Hormé.

Winnicott, D. W. (2005). La naturaleza humana. Buenos Aires: Paidós.

Winnicott, D. W. (2007). Procesos de maduración y el ambiente facilitador. Buenos Aires: Paidós.

Winnicott, W. D. (1999). Acerca de los niños. Buenos Aires, Paidós. 